\title{
Intrahepatic bile duct strictures in a liver allograft recipient mimicking recurrent primary sclerosing cholangitis
}

\section{Follow-up of a case report}

\author{
G. G.Hartman, R. Gordon, J. Lerut, T. E.Starzl, and A.J. Demetris \\ Presbyterian University Hospital of Pittsburgh, DeSoto at O'Hara Streets, Pittsburgh, PA 15213-2582, USA
}

Received March 5. 1991/Accepted April 5, 1991

Sir: Reasons for development of large biliary tract complications after orthotopic liver transplantation (OLT) are varied and include: (a) most commonly, surgical complications from reconstruction of the extrahepatic bile duct [2]; (b) occasionally. recurrence of malignant biliary tract disease [1]; and (c) debatably, recurrence of the original benign biliary tract disease $[5,6]$. Although a higher incidence of biliary tract complications in primary sclerosing cholangitis (PSC) patients versus other indications for liver transplantation has been reported [4], only 1 of our first 55 patients [3] grafted for PSC developed biliary tract abnormalities suggestive of recurrent primary disease.

This communication provides a follow-up of our exceptional patient for whom a detailed clinicopathologic history was previously provided [2.3]. The patient, with PSC and. at the time, 40 years old, underwent uneventful orthotopic liver transplantation in August 1984 (male donor. blood type identical); no HLA typing or crossmatch results were available. The biliary reconstruction was with end-to-side choledochojejunostomy reusing a previously constructed Roux-en-Y limb, the length of which was not mentioned in the operative report.

Convalescence was uneventful and the patient was discharged after 20 days with normal liver functions. After 5.5 months. he was readmitted because of an "obstructive" liver enzyme profile. and a percutaneous cholangiogram showed the presence of intrahepatic biliary strictures with a patent biliary anastomosis. A liver biopsy showed early changes of bile duct obstruction without evidence of rejection. viral infection. or drug toxicity. At two other admissions in the next 3 months. liver biopsies showed similar changes, but with progressive portal fibrosis. The arterial and venous allograft vasculature were normal with ultrasound. Case reports were written at this time [2] suggesting that there had possibly been a recurrence of PSC. This conclusion appeared to be strengthened in the subsequent 24 27 months. during which the total serum bilirubin fluctuated between 2.0 and $2.5 \mathrm{mg} / \mathrm{dl}$. although the patient was clinically stable [3]. Thereafter, he began to have fatigue.

Offprint requests to: G. G. Hartman deepening jaundice. and pruritus. Liver biopsy still had features of duct obstruction but now with focal small bile duct loss. Repeat percutaneous transhepatic cholangiography showed multiple intra- and extrahepatic biliary strictures. Total bilirubin had increased to $10.0 \mathrm{mg} / \mathrm{dl}$, alkaline phosphatase was $1300 \mathrm{IU} / \mathrm{l}$, and gamma glutamyl transpeptidase was $836 \mathrm{IU} / 1$. On 18 August 1989, an uneventful hepatic retransplantation from a blood group and sex-identical donor was performed. There was a twoantigen HLA match and the cytotoxic crossmatch was negative. During the retransplantation, the ascending limb of the Roux-en-Y loop was noted to be less than $20 \mathrm{~cm}$ (standard is $40-45 \mathrm{~cm}$ ).

The failed graft weighed 1780 grams and was bilestained. The vascular supply was intact. Histologically. the irregularly dilated large ducts had severe acute ascending cholangitis and focal small bile duct loss. Partially digested vegetable matter was seen embedded in a severely inflamed intrahepatic bile duct (Fig. 1). On the basis of this finding and a short Roux-en-Y limb, we believe that we were incorrect in our earlier conclusion that sclerosing

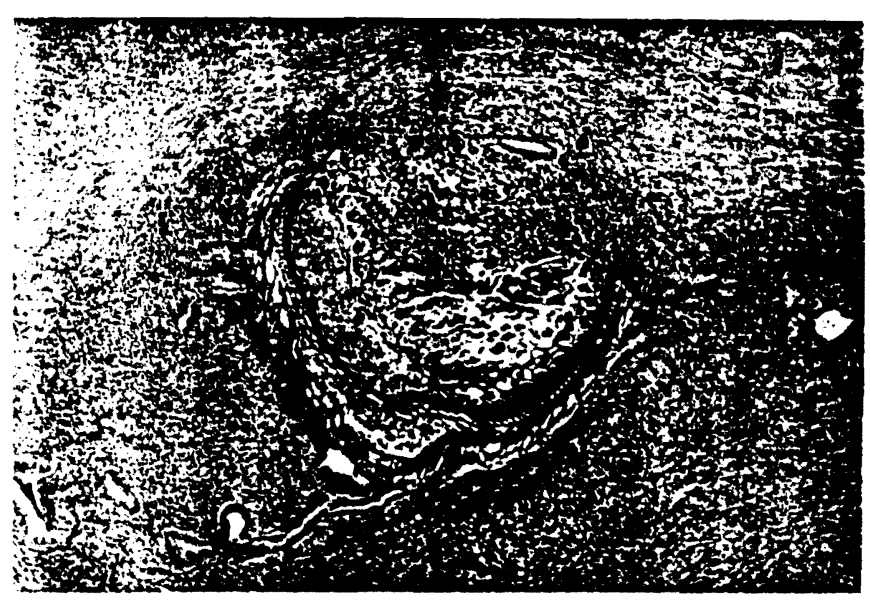

Fig. 1. Large bile duct with intraluminally embedded vegetable material with extensive acute inflammatory reaction surrounded by fibrosis 
cholangitis had possibly recurred. Instead. regurgitation of food into the intrahepatic biliary tree appeared to have been responsible for the clinicopathologic events. We cannot, however, completely exclude an antibody-related injury since crossmatch results for the first transplant were not available.

The patient has been well since retransplantation. at which time a Roux limb of conventional length was constructed for the new choledochojejunostomy. If the pathogenesis of the problem had been realized early after the first grafting, retransplantation could possibly have been avoided.

\section{References}

1. Iwatsuki S. Starzl TE. Gordon RD. Esquivel CO. Todo S, Tzakis A. Makowka L. Marsh JW. Miller CM (1987) Late mortality and morbidity after liver transplantation. Transplant Proc 19: 2373 2378

2. Lerut J. Gordon RD. Iwatsuki S. Shaw BW Jr. Esquivel CO, Tzakis A. Starzl TE (1987) Biliary tract complications in 393 human liver transplantations. Transplantation 43: 47-51

3. Lerut J. Demetris AJ. Stieber AC. Marsh JW. Gordon RD. Esquivel CO, Iwatsuki S. Starzl TE (1988) Intrahepatic bile duct strictures after human orthotopic liver transplantation. Transplant Int 1: $127-130$

4. Letourneau JG, Day DL. Hunter DW, Ascher NL, Najarian JS, Thompson WM. Castaneda-Zuniga WR (1988) Biliary complications after liver transplantation in patients with preexisting sclerosing cholangitis. Radiology 167:349-351

5. Marsh JW. Iwatsuki S, Makowka L, Esquivel CO, Gordon RD, Todo S. Tzakis A. Thiel D van. Starzl TE (1988) Orthotopic liver transplantation for primary sclerosing cholangitis. Ann Surg 207: 21-25

6. Neuberger J. Portmann B. MacDougall B. Calne RY, Williams R (1982) Recurrence of primary biliary cirrhosis after liver transplantation. N Engl J Med 306: 1-4 